\title{
Response in the newborn to raised upper airway resistance
}

\author{
MICHAEL PURCELL \\ From the Department of Paediatrics, London Hospital Medical College
}

\begin{abstract}
Purcell, M. (1976). Archives of Disease in Childhood, 51, 602. Response in the newborn to raised upper airway resistance. The effect of raising the airways resistance of 56 normal newborn babies by blocking alternate nostrils was studied by means of oesophageal intubation and the trunk plethysmograph. Increased resistance was associated with reduced respiratory rate and ventilation. A comparison was made of the response in different sleep states. In rapid eye movement (REM) sleep respiratory tidal volume decreased on blocking, there was no increase in the work of breathing and the fall in minute volume was greater than in non-REM sleep where tidal volume and minute work increased on blocking. These responses may be relevant to the sudden unexpected death syndrome in infancy, and to the management of normal newborns.
\end{abstract}

The newborn baby, because he is an obligatory nose-breather, is more dependent on the nasal airway than at any other time in his life. This dependence, which has been related to the high position of the epiglottis in the newborn and compared with the nasopharyngeal anatomy of nose-breathing mammals (Polgar and Kong, 1965), makes the newborn particularly vulnerable to nasal obstruction. Asphyxial death in congenital choanal atresia can be the price of this inability to mouth breathe. In choanal stenosis where respiratory work is greatly increased, or in normal babies it is very unusual to see mouth breathing, and nasal obstruction has been suggested as a cause of sudden, unexpected death in infancy (Shaw, 1970).

The importance of sleep state in the assessment of the newborn has become widely recognized. Respiratory frequency has been shown to be higher and respiration less regular in the sleep state characterized by rapid eye movements (REM) rather than in non-REM sleep (Prechtl, 1968). Investigating oxygen consumption in sick and low birthweight newborns, Scopes and Ahmed (1966) found higher levels in REM sleep. In normal infants minute volume is higher in REM sleep (Bolton and Herman, 1974). The effect of sleep state on airways resistance measurements seems not to have been reported.

Received 4 December 1975.
Cross and Lewis (1971) have shown that a sleeping infant can tolerate upper airway obstruction without waking even when tidal volume is reduced. This report presents further observations of the response in the newborn to increased airway resistance in different sleep states.

\section{Materials and methods}

The subjects were normal, term newborn babies; 28 boys and 28 girls, aged from 1 to 11 days with weights ranging from 2380 to $3905 \mathrm{~g}$ (mean $3116.5 \mathrm{gm}$ ). No sedation was used. They were taken from the maternity ward nurseries with the informed consent of their mothers who were sometimes present while their babies were being studied.

Intra-oesophageal pressure as an index of intrapleural pressure was measured with a $4 \mathrm{~cm}$ air-filled, latex balloon mounted on a 6 FG feeding tube. This was passed through the baby's mouth to approximately $15 \mathrm{~cm}$, placing the balloon in the lower oesophagus. Respiratory tidal volume was measured with the trunk plethysmograph, the infant being supine with a pneumatic cuff round his face to complete the seal (Cross, 1949).

The signals from oesophageal and plethysomograph pressure transducers were displayed, with continuous limb-lead electrocardiogram on an oscilloscope screen (Sanborn 780-6 Visoscope) and recorded on tape (SE 84 Recorder). Exhaled $\mathrm{Co}_{2}$ was intermittently monitored by sampling from the nostrils (Beckman Gas Analayzer LB-1). The recording was later played back at selected paper speeds for analysis on a four-channel pen recorder 
(Sanborn 7764 A). Pressure-volume loops could be displayed on the oscilloscope or reproduced from the tape on an XY recorder.

The mean of ten figures for airways resistance was calculated from consecutive inspirations and expirations on sections of the trace before and after altering the resistance, as close together as was compatible with the need for regular complexes. Airways resistance was measured as the ratio of total pressure change to the corresponding change of flow between points on the trace of equal lung volume. A simplified formula was used to calculate the work of breathing: work (in $\mathrm{g} \mathrm{cm} / \mathrm{min}$ ) $=0.6 \mathrm{PV}$, where $P$ is the total pressure change in $\mathrm{cm} \mathrm{H}_{2} \mathrm{O}$ during the respiratory cycle and $\mathrm{V}$ the minute volume (Cook et al., 1957). Respiratory frequency and minute volume, from which the tidal volume was calculated, were obtained from one-minute sections of trace which included those complexes used for calculating the corresponding airways resistance. Mean oesophageal pressure change was derived from ten successive breaths in the same section.

Airways resistance was increased by lightly placing a finger on alternate nostrils. The infant's nose is rarely symmetrical so the comparative air flows from each nostril were assessed by sampling with a $\mathrm{CO}_{2}$ analyser and the smaller nostril blocked first. When the stream of exhaled air is small it is more readily diluted by surrounding air; sampling registers a decreased concentration of $\mathrm{CO}_{2}$ from which an impression of the relative functional sizes of the nostrils can be obtained. Blocking was continued for about a minute after any initial restlessness had subsided unless the infant seemed distressed, or the tidal volume was obviously inadequate. Occasionally exhaled $\mathrm{CO}_{2}$ levels increased during blocking; when this happened the block was released. A few minutes after blocking the first nostril, the other side was similarly blocked.

Sleep state was described as rapid eye movement (REM) or non-REM, according to the criteria of Prechtl and Beintema (1964). REM sleep corresponds to the authors' 'state two' where movements of the eyes are seen beneath closed lids and frequent small movements of limbs and facial muscles occur. Non-REM sleep, the authors' 'state one', is characterized by the absence of eye movements and motor activity, apart from startles and short trains of spontaneous sucking.

The experience of Bolton and Herman (1973) using an electro-oculogram method of detecting REMs suggested that the observation of eye movements is a reliable way of identifying sleep state. Lenard (1970) describes slow and rapid eye movements occurring continuously under closed or partially closed lids as the most prominent feature of REM sleep and that these are particularly numerous in the newborn period. They are easily observed with infants in the trunk plethysmograph even when their eyes are closed. With some babies an attempt was made to record the effects of nose blocking in both sleep states.

\section{Results}

Single nostril blockage is usually well tolerated by the sleeping newborn. It was noticed on several occasions that the moment of blocking an infant in REM sleep seemed to coincide with transition to non-REM sleep. Sometimes when the asymmetry of the nostrils was great and the larger nostril blocked, the baby would make increasing respiratory efforts and start to cry. No infant breathed through his mouth throughout this study except when crying. In a preliminary survey of undisturbed babies in the maternity ward nurseries exhaled $\mathrm{CO}_{2}$ sampling showed that out of 200 babies only 2 were using their mouths to breathe and these were breathing through their noses at the same time.

Blocking either of an infant's nostrils always caused a measurable increase in airways resistance. Fig. 1 shows a typical section of trace where

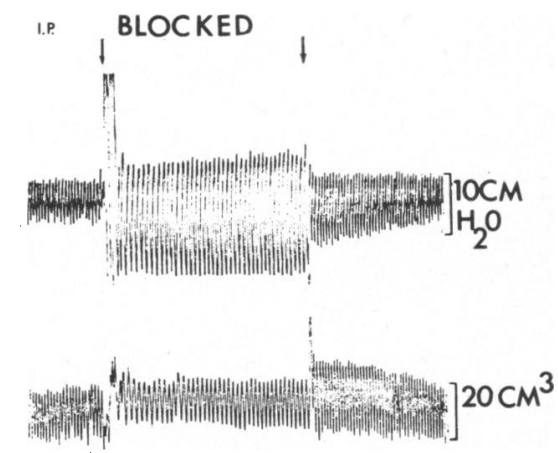

Fig. 1.-Section of trace at $1 \mathrm{~mm} / \mathrm{s}$ paper speed. Oesophageal pressure above, tidal volume below; showing the effect of blocking one nostril.

blocking the larger nostril in non-REM sleep increased resistance from $84 \mathrm{~cm} \mathrm{H}_{2} \mathrm{O} / 1$ per sec to $501 \mathrm{~cm} \mathrm{H}_{2} \mathrm{O} / 1$ per sec. At the same time respiratory frequency decreased by $32 \%$ and the minute volume by $29 \%$. There was a compensatory increase in ventilation on unblocking. The effect of blocking on the calculated resistance is shown in Fig. 2 where the unblocked resistance is compared with the results of blocking smaller and larger nostrils in those babies who tolerated the manoeuvre. The mean resistance unblocked was $46.1 \mathrm{~cm}$ $\mathrm{H}_{2} \mathrm{O} / 1$ per sec, with smaller nostrils blocked 78.9 $\mathrm{cm} \mathrm{H}_{2} \mathrm{O} / 1$ per sec, and with the larger nostril blocked $179 \cdot 3 \mathrm{~cm} \mathrm{H}_{2} \mathrm{O} / 1$ per sec. Slowing of respiration seemed to occur consistently with a rise in resistance. The effect on tidal volume was variable but there was seldom an increase sufficient to compensate for the lowered frequency and the result was a decrease in ventilation (Figs. 3, 4). 


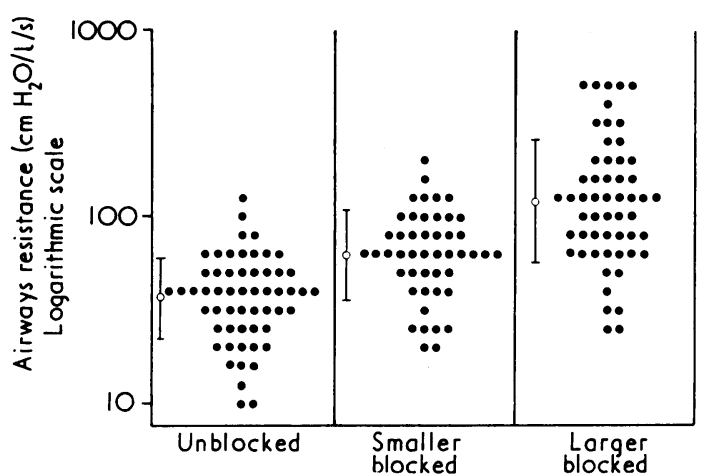

FIG. 2.-Airways resistance: unblocked, and with smaller and larger nostrils blocked. Mean and standard deviation shown.

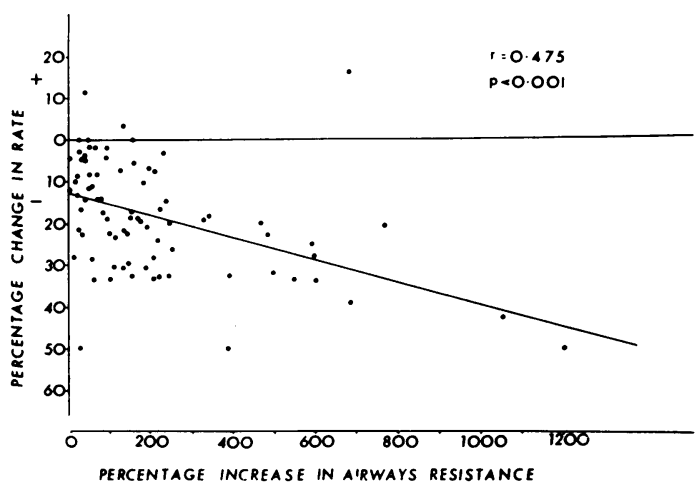

FIG. 3.-Effect on respiratory frequency of a rise in resistance.

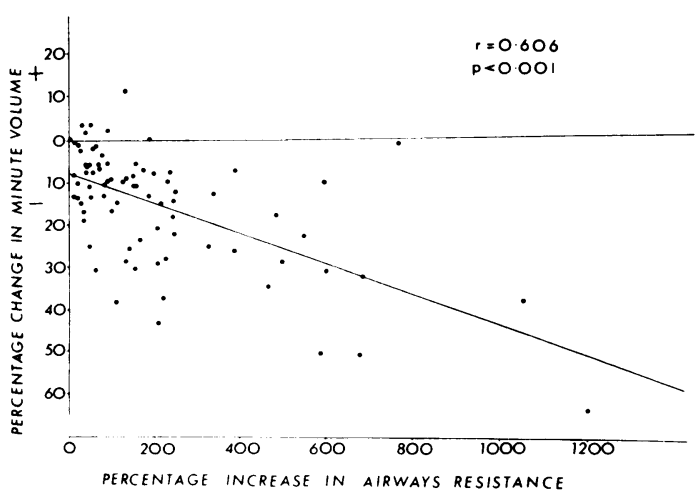

FIG. 4.-Effect on minute volume of a rise in resistance.
The work of breathing is represented by the area of a loop generated by plotting pressure against volume throughout a complete respiratory cycle. Fig. 5 shows examples of loops before and
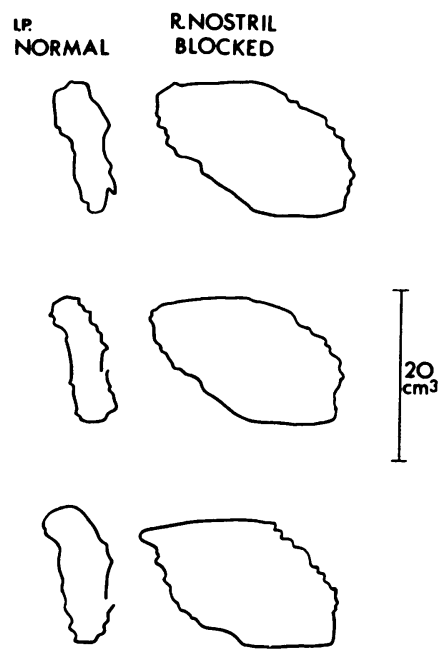

Ocm Ho'

Fig. 5.-Pressure ( $x$ axis)-volume (y axis) loops before and during nostril block, from the same section of trace as in Fig. 1.

after blocking, the breaths being taken from the section of trace shown in Fig. 1. In this case the tidal volume has not altered on blocking but the increase in oesophageal pressure swing has trebled the area of the loop, suggesting a threefold increase in the work of breathing. The mean, unblocked minute work of all the babies studied was $2526.5 \mathrm{~g}$ $\mathrm{cm} / \mathrm{min}$ (SEM 141.7). This increased on blocking the larger nostril to a mean of $3281.2 \mathrm{~g} \mathrm{~cm} / \mathrm{min}$ (SEM 182 2).

The trunk plethysmograph is not well adapted to detecting alterations in functional residual capacity because any leak, which would be negligeable in the measurement of ventilation, would conceal a gradual change in thoracic volume. However, on a few occasions, when the increase in resistance on blocking was large, the end-expiratory position on the volume trace rose progressively suggesting an increase in functional residual capacity. Fig. 6 shows the thoracic volume increasing progressively during two periods of blockage and returning to normal on release of the obstruction. 


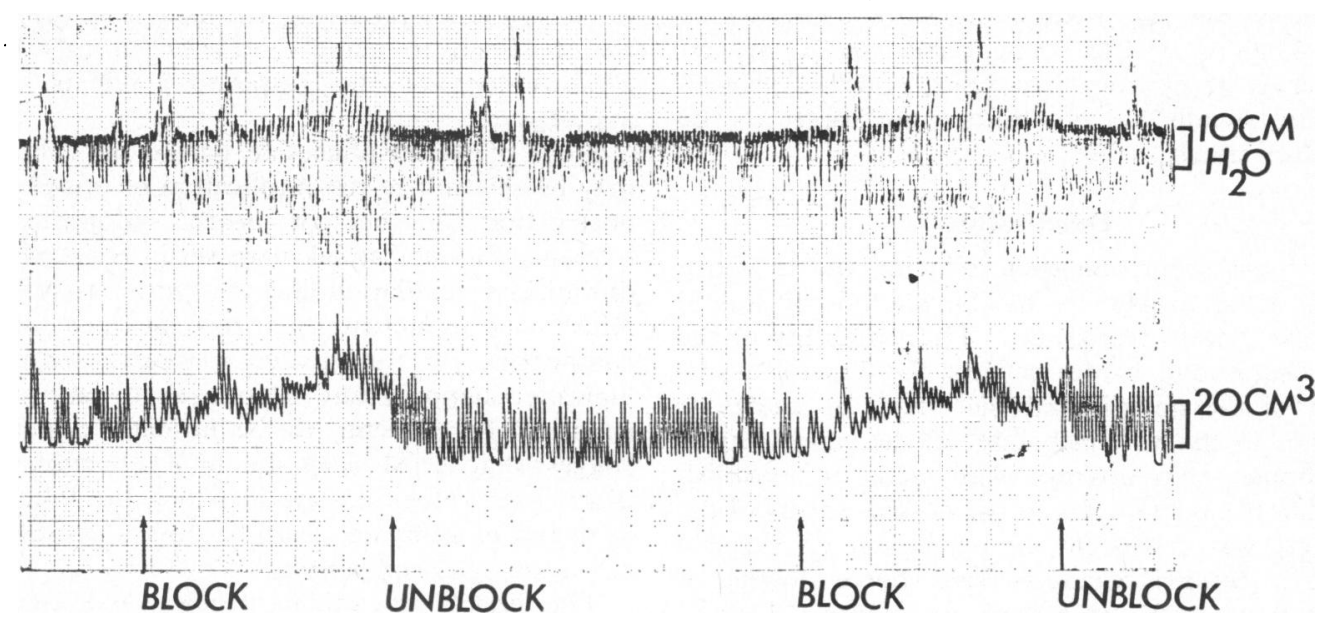

Fig. 6.-Two periods of blockage during which oesophageal pressure swings increase (above), with a rise in the endexpiratory position on the volume trace (below) suggesting an increase in functional residual capacity.

Inspiration time/expiration time ratios were studied in 31 of the babies by measuring the relative lengths of each component of respiration on the tidal volume trace. Before blocking the mean ratio of inspiration to expiration was $1: 1 \cdot 47$ and there was little change in this ratio on blocking though both lengthened with the overall slowing of respiration. However, dividing this group into babies in REM and in non-REM sleep, there was a tendency for the prolongation of expiration to be greater than that of inspiration in REM sleep. (Inspiration/expiration ratio during blockage: REM sleep $1: 1 \cdot 65$, non-REM sleep $1: 1 \cdot 37$ ).

Exhaled $\mathrm{CO}_{2}$ levels were monitored during blocking and on some occasions an increasing concentration was recorded, but this returned to normal in a few breaths on unblocking. Recorded $\mathrm{CO}_{2}$ levels varied from $4.7 \%$ (equivalent to a $\mathrm{PCO}_{2}$ of $\left.34 \mathrm{mmHg}\right)$ to $7.4 \%(52.9 \mathrm{mmHg})$. No change was detected in the electrocardiogram on blocking in any infant. The cardiac frequency showed only slight variations but in no consistent direction.

A comparison of mean results for babies in different sleep states showed significant differences $(P<0.05)$ in unblocked resistance, minute volume, minute work, and oesophageal pressure swings (Table). Respiratory frequency was generally higher in REM sleep but the difference did not reach significance in this study. Tidal volumes were similar in both sleep states.

The response to blocking was found to vary with sleep state in three respects. Firstly, tidal volume tended to decrease on blocking in REM sleep and increase in non-REM sleep $(P<0.05)$. Secondly, the fall in minute volume on blocking was greater in REM sleep $(P<0.05)$. Lastly, in REM sleep the infant did not increase the work of breathing on

TABLE

Mean results in REM sleep (12 babies) and non-REM sleep (41 babies) ( \pm standard errors of mean)

\begin{tabular}{|c|c|c|c|c|}
\hline \multirow[b]{2}{*}{ Sleep state } & \multicolumn{2}{|c|}{ Unblocked } & \multicolumn{2}{|c|}{ Blocked } \\
\hline & REM & Non-REM & REM & Non-REM \\
\hline
\end{tabular}

*Pairs of observations showing a significant $(P<0.05)$ difference between sleep states. 
blocking, but a slight decrease was recorded, while in non-REM sleep the minute work increased by over $40 \%(P<0.01)$. The responses of airways resistance, respiratory frequency, and oesophageal pressure swings did not differ significantly in the two sleep states.

\section{Discussion}

It is not surprising that reducing the newborn baby's nasal airway by blocking a nostril should increase airways resistance. The variability of the response among babies reflects the natural asymmetry of the nostrils and the effects of mucus or changes in the vascular state of the nasal mucus membrane. No attempt was made to establish whether the relative size of the nostrils in any of the subjects was consistent, or dependent on variable factors. Studies of adults have shown slowing of respiration with increased resistance (Davies, Haldane, and Priestley, 1919; McIlroy et al., 1956), but the reported effects on ventilation have been inconsistent. Increased oesophageal pressure swings represent the infant's efforts to maintain a constant tidal volume in spite of increased resistance. The increased pressure was not sufficient to maintain the unblocked rate of flow through the nose and both expiration and inspiration times were prolonged with the effect of reducing respiratory frequency and minute volume.

The greater airways resistance in REM sleep, with increased minute work and oesophageal pressure swings follows from the increased ventilation in that state compared with non-REM sleep; for example there will be more turbulence in the airways at higher rates of flow. The responses to blocking of resistance, frequency, and pressure swings were similar in either state but the failure of minute work to increase in REM sleep with the greater fall of minute volume than in non-REM sleep were unexpected findings. They suggest variations in the neurological control of respiration in the two sleep states.

Swift and Emery (1973) studied newborns and 6-week-old infants during short periods of complete nasal occlusion and showed that the response varied with sleep state. The babies in REM sleep tended to respond more slowly to blockage by struggling or mouth breathing, and some failed to show any significant reaction. The proportion on nonresponders was higher in the older group. It was suggested that it might be possible to predict infants at risk of sudden unexpected death and it is interesting that the older babies seemed to be more vulnerable, as the syndrome seldom occurs in the first month of life. The authors also reported the response to unilateral nasal blockage which was said to be minimal, reflecting the fact that the report was confined to clinical observation rather than measurement of the respiratory effects of the manoeuvre.

Some of the responses to partial nasal blockage may be relevant to the implication of upper airway obstruction in the cot death syndrome. The tolerance for substantial increases in resistance with diminished ventilation and the failure of infants in REM sleep to increase their minute work output to compensate for the greater resistance are physiologically inappropriate responses to an external stress. There seems to be enough evidence to suggest that REM sleep should be thought of as a distinct neurological state in which the infant may be at risk of asphyxial death because of modification of physiological responses.

The effects of unilateral nasal blockage have implications for the routine care of newborn infants. A congenitally small airway or obstruction with mucus produce similar levels of airways resistance to those seen in this study. The use of indwelling nasogastric tubes in the feeding of sick babies or those of short gestation is an avoidable cause of nasal obstruction.

I am grateful to Professor K. W. Cross who is in receipt of a generous grant from the Foundation for the Study of Infant Deaths, to members of the Department of Physiology of the London Hospital Medical College, and to Miss Ruth Warner for assistance throughout this project.

\section{REFERENCES}

Bolton, D. P. G., and Herman, S. (1974). Ventilation and sleep state in the newborn. Fournal of Physiology, 240, 67.

Cook, C. D., Sutherland, J. M., Segal, S., Cherry, R. B., Mead, J., McIlroy, M. B., and Smith, C. A. (1957). Studies of respiratory physiology in the newborn infant. III. Measurements of mechanics of respiration. fournal of Clinical Inivestigation, 36, 440.

Cross, K. W. (1949). The respiratory rate and ventilation in the newborn baby. Fournal of Physiology, $109,459$.

Cross, K. W., and Lewis, S.R. (1971). Upper respiratory obstruction and cot death. Archives of Disease in Childhood, 46, 211.

Davies, H. W., Haldane, J. S., and Priestley, J. G. (1919). Responses to respiratory resistance. Fournal of Physiology, 53, 60.

Lenard, H. G. (1970). Sleep studies in infancy. Acta Paediatrica Scandinavica, 59, 572.

McIlroy, M. B., Eldridge, F. L., Thomas, J. P., and Christie, R. V. (1956). The effect of added elastic and non-elastic resistances on the pattern of breathing in normal subjects. Clinical Science, 15, 337.

Polgar, G., and Kong, G. P. (1965). The nasal resistance of newborn infants. Fournal of Pediatrics, 67, 557.

Prechtl, H. F. R. (1968). Polygraphic studies of the full-term newborn: II. Computer analysis of recorded data. Clinics in Developmental Medicine, No. 27., p. 1. Ed. by R. MacKeith and M. Bax. Heinemann, London.

Prechtl, H. F. R., and Beintema, D. J. (1964). Neurological examination of the full-term newborn infant. Clinics in Developmental Medicine, No. 12. Heinemann, London. 
Scopes, J. W., and Ahmed, I. (1966). Minimal rates of oxygen consumption in sick and premature newborn infants. Archives of Disease in Childhood, 41, 407.

Shaw, E. B. (1970). Sudden unexpected death in infancy syndrome. American fournal of Diseases of Children, 119, 416.

Swift, P. G. F., and Emery, J. L. (1973). Clinical observations on response to nasal occlusion in infancy. Archives of Disease in Childhood, 48, 947.

Correspondence to Dr. M. Purcell, Derbyshire Children's Hospital, North Street, Derby DE1 3BA. 